BJHS: Themes 2: 215-234, 2017. C British Society for the History of Science 2017. This is an Open Access article, distributed under the terms of the Creative Commons Attribution licence (http://creativecommons.org/licenses/by/4.0/), which permits unrestricted re-use, distribution, and reproduction in any medium, provided the original work is properly cited.

doi:10.1017/bjt.2017.2 First published online 2 March 2017

\title{
Bovine and human becomings in histories of dairy technologies: robotic milking systems and remaking animal and human subjectivity
}

\author{
LEWIS HOLLOWAY* AND CHRISTOPHER BEAR**
}

\begin{abstract}
This paper positions the recent emergence of robotic or automatic milking systems (AMS) in relation to discourses surrounding the longer history of milking technologies in the UK and elsewhere. The mechanization of milking has been associated with sets of hopes and anxieties which permeated the transition from hand to increasingly automated forms of milking. This transition has affected the relationships between humans and cows on dairy farms, producing different modes of cow and human agency and subjectivity. In this paper, drawing on empirical evidence from a research project exploring AMS use in contemporary farms, we examine how ongoing debates about the benefits (or otherwise) of AMS relate to longer-term discursive currents surrounding the historical emergence of milking technologies and their implications for efficient farming and the human and bovine experience of milk production. We illustrate how technological change is in part based on understandings of people and cows, at the same time as bovine and human agency and subjectivity are entrained and reconfigured in relation to emerging milking technologies, so that what it is to be a cow or human becomes different as technologies change. We illustrate how this results from - and in - competing ways of understanding cows: as active agents, as contributing to technological design, as 'free', as 'responsible' and/or requiring surveillance and discipline, and as efficient co-producers, with milking technologies, of milk.
\end{abstract}

\section{Introduction}

This paper aims to examine the emergence of robotic or automatic milking systems (AMS) in relation to persistent issues and anxieties associated with the longer history of the development and science of milking technologies in the UK and elsewhere. AMS is often represented as a radical change in milking technologies and practices; its manufacturers claim that it is the future of dairy farming. However, in this paper we argue that, although AMS deploys recently available robotic and information

* School of Environmental Sciences, University of Hull, Cottingham Road, Hull, HU6 7RX, UK. Email: 1.holloway@hull.ac.uk.

* School of Geography and Planning, Cardiff University, Cardiff, CF10 3AT, UK. Email: bearck@cardiff. ac.uk.

Some of the research for this paper was conducted as part of an ESRC research project called Robotic and Information Technologies in Livestock Agriculture: New Relationships between Humans, Cows and Machines, RES-062-23-2086. 
technologies, it can be examined in terms of a longer history of sets of hopes and anxieties surrounding changing milking technologies. The paper is thus interested in how issues associated with the history of machine milking in general become played out in the relatively new context of AMS, as well as how these new technologies transform dairy farming. In the case of AMS, the technology has led to some significant changes in how both humans and cows use space and act in their everyday lives; in the expectations and demands placed on humans and cows; and in how humans and cows encounter, experience and interact with each other. ${ }^{1}$

Beginning with issues that arose in relation to early attempts to mechanize milking in the later nineteenth century in the UK and the USA, the paper examines the implications of a shift to machine milking for people, cows and human-cow relationships. After describing AMS and the claims made for its superiority over 'conventional' milking machines, the paper describes our empirical research into AMS on UK dairy farms. It then shows how historical concerns about machine milking persist and take on new inflections in relation to the relatively recent emergence of AMS. We are interested throughout in how scientific approaches to dairy cows and milking, and the technological research and development process involved in actually designing AMS, are tied up with understandings of the bodies, agencies and subjectivities of the bovines and humans who become expected to co-produce milk with robots.

In doing so, we follow recent post-structuralist writing to begin from the premise that (human and bovine) agency and subjectivity are not innate or fixed, but immanent. ${ }^{2}$ As such, agency (what humans and cows can do) and subjectivity (what humans and cows experience, and how they are represented and expected to behave in certain ways) are neither simply withheld nor liberated in association with particular technologies. Instead, they emerge alongside the development of technologies (and in different farming systems more widely). It is in this sense that we refer to their 'becoming' in relation to the technologies they are associated with. Our view is that the agencies and subjectivities - of both cows and humans - and technologies are co-produced, in what can be referred to as human-animal-technology relations. Technologies are created and used in situations partly on the basis of assumptions (which may be right or wrong) about, and experience of, what bovine and human 'users' of the technologies are like. At the same time, encountering and 'using' the technologies change what it is to be human or bovine. New ways of surveilling and capturing bovine agency can also be associated with recent robotic and information technologies, enabling new means of intervening in and exploiting cows' bodies and behaviours. Cows can be seen as in some ways contributing (albeit unwittingly), through their embodied subjectivity and agency, to technological change

1 Lewis Holloway, 'Subjecting cows to robots: farming technologies and the making of animal subjects', Environment and Planning D: Society and Space (2007) 25, pp. 1041-1060; Lewis Holloway, Christopher Bear and Katy Wilkinson, 'Re-capturing bovine life: robot-cow relationships, freedom and control in dairy farming', Journal of Rural Studies (2014) 33, pp. 131-140; Lewis Holloway, Katy Wilkinson and Christopher Bear, 'Robotic milking technologies and renegotiating situated ethical relationships on UK dairy farms', Agriculture and Human Values (2014) 31, pp. 185-199.

2 Bruno Latour, Politics of Nature: How to Bring the Sciences into Democracy, Cambridge, MA: Harvard University Press, 2004. 
and to ongoing exploitation of farmed animals (who might, indeed, be seen as technological artefacts themselves due to prolonged histories of human intervention in their lives and bodies ${ }^{3}$ ). Bovine and human agencies are thus expressed in new ways with emergent technologies: what it becomes possible for cows and humans to do and be is reconfigured in ways which can be represented concurrently as both beneficial and detrimental, as the paper explores.

In our analysis, we are cognizant of how, in all systems, dairy cows are likely to suffer restriction, pain, discomfort and exploitation. We do not, then, offer a story where a shift from more confined dairying systems to a more 'enlightened' approach to the bovine 'freedom' claimed for AMS liberates cows and necessarily provides for better bovine health, welfare and quality of life. Rather, we are interested in the embodied human and non-human experiences, and the discursive frameworks, surrounding these changes and the human-animal-technology co-productions involved.

\section{Milking machines: emergent anxieties}

Despite the existence of archival material associated with the science and technical development of mechanized milking technologies, and with responses to the health and welfare issues associated with them, there is surprisingly little sustained social-scientific analysis of the implications of the introduction of mechanized milking technologies, ${ }^{4}$ although there are several accounts of the development of milk production and consumption which necessarily address other associated technologies, particularly those associated with assuring milk quality. ${ }^{5}$ In this section, therefore, we examine some materials which deal with the shift from hand to machine milking, ${ }^{6}$ establishing a historical context for more recent debates around AMS, while also examining the development of hopes and anxieties inspired by attempts to mechanize the milking process.

Since the advent of the earliest milking machines in the mid-nineteenth century, mechanized milking has demanded the immediate, embodied involvement of a human being. Earlier attempts, for example, relied on a human inserting a tube into a cow's teat, allowing milk to flow out. ${ }^{7}$ Such 'catheter milking' was not always successful

3 Edmund Russell, 'The garden in the machine: toward an evolutionary history of technology', in Susan Schrepfer and Philip Scranton (eds.), Industrialising Organisms: Introducing Evolutionary History, London: Routledge, pp. 1-16.

4 But see Abigail Woods, 'Science, disease and dairy production in Britain, c.1927 to 1980', Agricultural History Review (2014) 62, pp. 294-314.

5 Peter Atkins, Liquid Materialities: A History of Milk, Science and the Law, Farnham: Ashgate, 2010; Kendra Smith-Howard, Pure and Modern Milk: An Environmental History since 1900, Oxford: Oxford University Press, 2013; Deborah Valenze, Milk: A Local and Global History, New Haven, CT: Yale University Press, 2011.

6 For an overview see D.N. Akam, Technical Development of Milking Machines, Mechanisation and Automation of Cattle Production Occasional Publication No 2, Cambridge: British Society of Animal Production, 1980.

7 Madison Goulart, 'A history, description and comparison of different brands of dairy parlor equipment and which designs are the best fit for different sized dairy operations: a senior project presented to the Faculty of the Dairy Science Department, California Polytechnic State University, San Luis Obispo', March 
and tended to damage the udder and cause distress to the cow. ${ }^{8}$ More sophisticated attempts to develop machine milking attempted to replicate the sucking action of a calf, encouraging the cow to 'let down' milk in response to the suction generated by a pump. ${ }^{9}$ Goulart notes, for example, the acquisition of a patent by Hodges and Brockenden for a vacuum milking machine in England in 1851, ${ }^{10}$ while Brassley records that 237 patents were awarded for milking-machine technologies between 1860 and 1915, although many of these were 'of dubious worth'. ${ }^{11}$ The emergence of a more successful technology depended on the combination of technologies such as the Struthers and Weir pulsator in 1892, and the Gillies teat cup in 1902. ${ }^{12}$ Machines such as the Murchland machine were amongst the first commercially available technologies, patented in 1892 and marketed from 1889. ${ }^{13}$ The milker would move from cow to cow, as they had done when hand milking into a bucket, taking the portable 'bucket' milking machine with them and milking each animal individually. Cows would remain in their stalls to be milked, in the same place as they ate and slept. Yet despite the increasing availability of effective milking machines, by 193990 per cent of UK herds were still hand milked. It was only during the post-war period that machine milking became dominant, reaching 85 per cent of herds by $1961 .{ }^{14}$

What is now regarded as 'conventional' machine milking has evolved incrementally from this technology so that electrical or diesel-fuelled pumps became able to milk multiple cows simultaneously. Milking 'parlours' thus evolved from the 1930s onwards, becoming more widely available from the $1950 \mathrm{~s} .{ }^{15}$ Increasing use of electronic and automatic technologies in milking parlours since the 1970s has allowed milking parlours and dairy herds to become larger, reducing the amount of labour needed per cow. ${ }^{16}$ Cows come into a specialist parlour space (away from their eating, grazing and resting areas) in groups, where a worker can milk each group. The herd is rounded up into a holding area, from which each group enters the parlour, and each individual enters a milking stall and receives some feed. The milker cleans each cow's udder and checks a sample of milk, and attaches the milking 'cluster' to the teats, and milking proceeds until the cow's milk flow reduces, at which point the cluster is removed by the milker

2014; Oscar Erf, 'Milking machines', Kansas State Agricultural College, Agricultural Experiment Station, Bulletin 140, 1906.

8 Richard Van Vleck, 'Early cow milking machines', American Artifacts: Scientific, Medical and Mechanical Antiques, at www.americanartifacts.com/smma/milker/milker.htm, accessed 25 May 2016.

9 Erf, op. cit. (7).

10 Goulart, op. cit. (7).

11 Paul Brassley, 'Output and technical change in twentieth-century British agriculture', Agricultural History Review (2000) 48, pp. 60-84, 73.

12 Brassley, op. cit. (11).

13 Goulart, op. cit. (7); Van Vleck, op. cit. (8); Douglas J. Reinemann, Graeme A. Mein and Misty DavisJohnson, 'Milking machine research: past, present and future', paper presented at the 42 nd annual meeting of the National Mastitis Council, Fort Worth, Texas, USA, 26-29 January 2003.

14 Brassley, op. cit. (11).

15 Edith Whetham, 'The mechanisation of British farming 1910-1945', Journal of Agricultural Economics (1970) 21, pp. 317-331; Henk Hogveen and Wijbrand Ouweltjes, 'Sensors and management support in hightechnology milking', Journal of Animal Science (2003) 81, pp. 1-10.

16 Hogveen and Ouweltjes, op. cit. (15). 
or, normally now, automatically. The cows are then released to return to the barn or the field. During milking, greater or lesser amounts of data are recorded, depending on the technological sophistication of the milking equipment. Recording of milk volume and composition is likely, along with measures which aim to identify possible health issues, especially mastitis, from the existence of blood cells in the milk. There are a number of variations on this pattern, in particular relating to the configuration of the group of cows during milking. But a feature of all these systems is that the cows are herded together, two or three times per day at times decided by the farmer, brought from the field or barn into a milking parlour spatially separated from their 'living' areas, milked in groups and then returned to feeding and resting spaces.

The introduction of parlour milking meant that cows more usually lived in a herd, rather than as individuals tethered in a stall. For people, close, embodied contact with individual cows shifted to a much more technologically mediated relationship. Several anxieties were associated with these changes.

Concerns about the mechanization of milking, especially in relation to mastitis, persisted from the 1920s onwards, as Woods shows in her paper on scientific framings of the disease. ${ }^{17}$ As she notes, there was a radical transformation in dairy farming, as more technologically driven systems were introduced, along with a move towards larger, but fewer, dairy herds. Mechanization was a key part of this process, including the increasing adoption of machine milking and the eventual all but elimination of hand milking in the UK. This agricultural revolution is often criticized for its negative impact on cow welfare - but as the different framings of mastitis show, the picture is rather more complex. Hand milking itself could be associated with mastitis, particularly where good milking practice and hygiene were not maintained - but the disease was also linked to the adoption of machine milking, which was being used with around one-third of dairy cows by the end of the Second World War. Machines were thought to be responsible for transferring bacteria between cows, and for damaging the udder itself: selective breeding for increased milk production was also producing cows with less resistance to the disease. Different perspectives on mastitis control could emphasize improved technology, the imposition of standardized milking practices which emphasized hygiene, and what Woods refers to as the 'indefineable quality known as good stockmanship' ${ }^{18}$ a concept which leads to an understanding of cow health as co-produced by technical procedure and human skill and knowledge gained by experience. In order to access this element of agricultural science, we move beyond the scientific and medical sources addressed by Woods, and consider some other accounts of agricultural change. These provide a sense of some of the currents of discussion which surrounded this profound shift in the milking experience for both people and cows.

John Seymour, self-sufficiency advocate and 'guru' for many from the 1960s onwards, in his particular perspective on Rural Life, ${ }^{19}$ viewed the introduction of milking

17 Woods, op. cit. (4).

18 Woods, op. cit. (4), p. 313.

19 John Seymour, Rural Life, Devizes: Collins and Brown Limited, 1991. 
machines as detrimental to the experience of the person responsible for milking. Although machine milking might enhance efficiency, he nevertheless wrote, 'It was a good woman or man who could hand milk a dozen cows twice a day. Now a person might milk 100 animals by machine but it is tedious work and there is no pleasure in it'. ${ }^{20}$ Seymour addressed the human experience here, but elsewhere he also discussed the nature of the cow ('a very gentle, beautiful creature'21), human-cow companionship and the intimacy associated with hand milking, which is by implication threatened by a move to machine milking. For example, he wrote evocatively of the multi-sensual experience of hand milking his cow:

I look forward now to the morning and evening milking. There seems to me to be a friendliness between the cow and me, I put my head in her old flank and I squirt away, and there is a nice smell, and a nice sound as the jets hiss into the frothing bucket ...22

John Collis's memoirs and commentary on agricultural labour during the Second World War focused, from a rather different perspective, on the unease and anxiety that characterized the transition from hand to machine milking. ${ }^{23}$ Collis argued that hand milking cows is as unnatural as machine milking them, and that the contemporary dairy cow is a human creation, having been bred to perform particular functions. But, echoing Heidegger's perspective on the effects of 'modern' technology, ${ }^{24}$ he was critical of the way that machine milking tended to promote a 'heartless' perspective on cows, ${ }^{25}$ treating them as machines too, a tendency enhanced by the focus in agricultural education on efficiency and productivity gains.

This recognition of the importance of productivity, in the context of concerns about the impact of this focus on cow health, is further developed in a series of publications addressed at educating and 'improving' farmers during and after the Second World War. They acknowledged that the shift to machine milking was not necessarily straightforward, and was associated with anxieties related to hygiene and to cow health. Fishwick, updating farmers on ongoing agricultural modernization actually during the war, mentioned the 'justifiable prejudice' which had existed around milking machines, linked especially to the difficulties of maintaining dairy hygiene. ${ }^{26}$ Similarly, Cattle at the Crossroads (transcripts of BBC-broadcast discussions between agricultural experts on the future of cattle breeding and farming techniques), included expressions of concern about milking machines, cow health and dairy hygiene. One commentator, for example, argued that mechanical milking took no account of cow individuality, particularly in terms of the length of the milking period: too long or short a time could lead

20 Seymour, op. cit. (19), p. 76.

21 John Seymour and Sally Seymour, Self-Sufficiency, London: Faber and Faber, 1973, p. 43.

22 John Seymour, The Fat of the Land, London: Faber and Faber, 1961, p. 42.

23 John Stewart Collis, The Worm Forgives the Plough, Harmondsworth: Penguin, 1975.

24 Martin Heidegger, 'The question concerning technology', in Heidegger, The Question Concerning

Technology and Other Essays (tr. William Lovitt), New York: Harper \& Row, 1977, pp. 3-35.

25 Collis, op. cit. (23), p. 87.

26 Victor Fishwick, Good Farming, London: The English Universities Press Limited, 1944, p. 58. 
to health problems in the cow. ${ }^{27}$ Mastitis remained a concern, as when veterinary surgeon N. Barron commented that mastitis usually appears 'when some change occurs - such as the change of a milker or the introduction of milking machines'. ${ }^{28}$ Expanding on this, the following exchange between the chair of the discussions, W.S. Mansfield, and Barron exemplifies the association between machine milking and health problems, which was to persist in subsequent and ongoing debates around improvements in milking technologies:

Mansfield: Now, in our last discussion the two people who joined in the talk were both considerable users of milking machines. Neither of them seemed to be very enthusiastic about them, particularly I think because they were very potent means of spreading disease unless very special precautions were taken and unless they were in the hands of skilled and careful people. Now, Barron, have you any recommendations to make to users of milking machines?

Barron: I must firstly admit they're very often used carelessly by ignorant people, but in my opinion they're safe if proper precautions are taken. For instance, some milk of every quarter should be drawn into a strip cup before the milking cups are put on - otherwise the existence of mastitis may be overlooked. ${ }^{29}$

Barron here refers to the practice of hand-drawing a little milk from each teat, and checking by eye for the mastitis-indicating presence of blood. What is expressed in these discussions is a mix of concerns about the skills and knowledgeability of the people involved in milking, the implications of the technology itself for the quality of the milking process, and the awareness of an association between milking technologies and the prevalence of diseases, especially mastitis.

These concerns continued to be expressed in later publications, such as The Other Man's Farm, based on the eponymous ABC Television series broadcast in the late 1950 s and early 1960s. ${ }^{30}$ Reporting on a set of what were regarded as model farmers, the mechanization of farming was assumed to be progressive: anxieties about hygiene and animal health were to be solved by scientific and technical fixes. For example, milking parlours could use lighting to encourage cows to move easily between different spaces, and there were discussions of what construction and bedding materials were most effective in maintaining hygiene. An awareness of cow behaviour and psychology seemed particularly important, so that in summarizing one modernized dairy farm, the author noted approvingly, 'Cows are not milking machines; they are individuals. The Dutch know this, and they study both breed characteristics and individual cow behaviour, profiting thereby'. ${ }^{31}$ This resonates with Collis's concern that the use of milking machines risks a concurrent representation of cows as machines, suggesting that there remained a concern that bovine individuality was in tension with the

27 W.S. Mansfield, A.B. Fowler and C. Higgs, 'How does the dairy cow earn her keep?', in Cattle at the Crossroads, Broadcast Discussions in the Home Service of the BBC on Cattle Breeding from the series 'Farming Today', Worcester: Littlebury and Company Ltd, 1944, pp. 35-42.

28 W.S. Mansfield, N. Barron and F. Russell Wood, 'How shall we keep her fit?', in Cattle at the Crossroads, op. cit. (27), pp. 43-51, 44.

29 Mansfield, Barron and Russell Wood, op. cit. (28), p. 47.

30 Franklin Engelmann, The Other Man's Farm, London: Weidenfeld and Nicolson, 1962.

31 Engelmann, op. cit. (30), p. 61. 
standardizing tendencies of mechanization, with potentially negative effects on cows' health and welfare.

From this material we identify three key themes. First, the subjectivity and experience of the cow changed, becoming something different as technologies changed from hand milking to machine milking. ${ }^{32}$ She risked being viewed and treated as a machine as focus shifted away from the 'constant contact with [the cow's] bodily parts and functions' which had been seen as central to caring for hand-milked cows in the nineteenth century. ${ }^{33}$ Second, the experience and subjectivity of the humans involved in milking were transformed in relation to technological change. Different demands were placed on them, the affective environment of milking was altered, and 'stockmanship' was given new inflections as technologies and milking practices changed. ${ }^{34}$ Third, the relationship between cows and people changed; a shift to machine milking could be seen to progressively alienate humans and cows from each other. Images of modern herringbone milking parlours, for example, render the cows all but invisible from the perspective of the 'pit' in which people labour underneath ranks of tails and udders, in comparison to Seymour's sensual description of hand milking his cow. Crucial to the changed nature of the human-cow relationship was a consistent concern with how progressive mechanization impacted on cow health, welfare and productivity, and how stockmanship could enable farmers to mitigate this.

We turn in the next section to examine these themes in relation to the emergence of robotic milking, examining how a historical trajectory of increasing mechanization, and now automation, carries them forward into new technological environments. Our focus is, again, on how bovine and human subjectivities and agency are co-produced, and become something different, with changing technologies.

\section{Robotic milking technologies}

Robotic milking is in part a response to some of the issues associated with conventional machine milking, particularly in relation to health, welfare and labour. Agricultural scientists in the Netherlands and the UK began the development of AMS in the 1980s, building on the availability of suitable industrial robotic and laser technologies and of cow-recognition technologies. The first commercial systems were installed on Dutch dairy farms in 1992. ${ }^{35}$

The scientists had to contend with several challenges, from automating the process of milking cluster attachment when cows have udders of different sizes and shapes, to surveilling cows during milking for disease while ensuring hygiene maintenance, and

32 Holloway, op. cit. (1).

33 Deborah Valenze, 'The art of women and the business of men: women's work and the dairy industry c.1740-1840', Past and Present (1991) 130, pp. 142-169, 160.

34 Deborah Butler and Lewis Holloway, 'Technology and restructuring the social field of dairy farming: hybrid capitals, “stockmanship" and automatic milking systems', Sociologia Ruralis (2015) 56, pp. 513-530.

35 Hogveen and Ouweltjes, op. cit. (15). 
incentivizing cows to attend the robot voluntarily for milking. ${ }^{36}$ Technical solutions to all but the last of these issues could be developed, for example using lasers for teat detection. However, in relation to cow incentivization, ethological research demonstrated that cows would not voluntarily attend a robot simply in order to be milked: milking per se was not sufficient motivation. Instead, the availability of concentrate feed within the robot is required. ${ }^{37}$ The following excerpts from an interview with a Dutch scientist involved in conducting AMS research in the 1980 give a sense of how the science of cow behaviour fed into the development of AMS technology:

the first experiment we did was so the cows used the cubicle houses, free stalls with cubicles. In the stalls there were these feeding stations for concentrate and the first experiment we did was adding a milking machine to the concentrate feeding station, asked some students from agriculture high school to be there twenty-four hours a day and they attached the milking machine when the cows came for eating the concentrate, so that was the beginning and the students were the robots, but that gave us already a lot of information of how often do the cows come and how does it work, what is the effect on the yield because the cows were milked more than two, normally the cows were milked twice a day and we saw already the first effect of this higher milking and we studied the behaviour of the cows, what happens with the pattern, because now they were continuously milked and not just at fixed times. ${ }^{38}$

...

... the main task of the research was how to integrate this automatic system in the farm and also in the farmer's routine of course, but in the beginning it was more to how could we make the cows come to this system by themselves ... so we got a lot of experience with that and a lot of $\mathrm{PhD}$ people worked on that and did a $\mathrm{PhD}$ on this work. Just studying the cow behaviour and what does this mean for the layout of the barn to make them visit the robot as often as needed ... oh yes, for the animal welfare, cows were high-yielding and when you milked them more often it was better for them, less mastitis ...

AMS, then, depended very much on an emergent scientific understanding of cows as a particular kind of living being, with specific behaviours and physiological qualities, rather than as the machine-like entities Collis feared they would be regarded as, as mechanization proceeded.

The robotic milking technology which emerged from this research altered the milking process in several important respects. It replaced conventional, twice-a-day, group milking with a system that, in theory, allowed cows to choose individually when to be milked. ${ }^{39}$ Humans are not immediately involved in the milking and thus need not be present. Each cow thus became 'responsible' for approaching the AMS stall to be milked. The AMS consists of the individual milking stall (one for approximately sixty cows each), a teat detection system and robotic arm for attaching the teat cups to the

36 Toby Mottram, 'Robotic milking: opportunities for improved dairy cow management', paper presented at the Dairy Cow Management and Welfare: What Difference Does Robotic Milking Make? seminar, Stoneleigh Park, Warwickshire, 17 November 2012.

37 Mottram, op. cit. (36).

38 Throughout, interviewee and organization names are withheld in order to protect confidentiality.

39 Albert Meijering, Henk Hogeveen and Kees de Koning (eds.), Automatic Milking: A Better Understanding, Wageningen: Wageningen Academic Publishers, 2004. 


\section{4}

Lewis Holloway and Christopher Bear

udder, a teat cleaning system, a computerized control system, and the milking system itself which is equivalent to the pump used in conventional milking. ${ }^{40} \mathrm{In}$ principle, cows can visit the AMS several times per twenty-four-hour period, at any time of the day or night, although the AMS can be programmed to restrict access to cows who attempt to enter the stall too many times in search of food rather than because they need to be milked. The AMS identifies cows individually by their RFID (radio frequency identification) tags; dispenses feed; and, during milking, can record a great deal of data, going beyond that usually recorded. For example, as well as overall milk yield, the AMS can record yield from each 'quarter' of the udder, and capture detailed data on milk composition and indicators of the presence of disease, to which the farmer can be alerted. The cow can also be weighed during milking, and a record kept of the number of times she visits the AMS, data which can be used as the basis of interventions by the farmer. The farmer is alerted to problems such as a breakdown via their mobile phone; they are also informed about cows which have not attended the AMS.

The advantages and disadvantages of automatic milking are contested. ${ }^{41}$ Manufacturers claim that AMS reduces labour costs, frees the farmer from the routine and drudgery of milking, increases milk yields and improves cow health and welfare. In contrast to the scheduled herd milking of conventional systems, cows have the choice of when to be milked, and can now be milked more frequently than twice per day. This more closely mimics the 'natural' process of suckling that a cow would experience if she was feeding her calf. ${ }^{42}$ The ability of the AMS to milk each quarter of the udder individually, according to the milk available, rather than milking all four quarters for the same length of time regardless of milk flow, is thought to reduce mastitis. Cow freedom and autonomy are emphasized in AMS, with the cow's ability to choose when to be milked contrasted with scheduled herd milking times. The effect is to constitute a new form of bovine subjectivity and agency. However, AMS also constrains cows in new ways, especially, and controversially, by encouraging the tendency to keep cows housed all year round, since cows out in fields some way from the robot will be less likely to return for milking. Such 'zero-grazing' practices are not restricted to AMS and are used in some conventionally milked herds too, but they are particularly associated with AMS because of the need to keep cows close to the robot.

To explore AMS introduction empirically, in 2010-2012 we carried out research at twenty UK dairy farms, half using AMS, half using conventional milking. Interviews with farmers focused on personal histories of involvement with dairy farming and milking technologies, and how changes in technology affected farming practices and relationships with their cows. We also carried out one-week periods of observational

40 Henk Hogeveen and Albert Meijering (eds.), Robotic Milking: Proceedings of the International Symposium held in Lelystad, the Netherlands, 17-19 August 2000, Wageningen: Wageningen Academic Publishers, 2000.

41 Jacylyn Jacobs and Janice Seigford, 'The impact of automatic milking systems on dairy cow management, behaviour, health and welfare', Journal of Dairy Science (2012) 95, pp. 2227-2247.

42 Lely, at www.lely.com/uploads/original/documents/Brochures/Farming_tips/Free_Cow_Traffic/Vrij_ koeverkeer_-_Brochure_-_EN.pdf, accessed July 2011. 
research on three case study farms using AMS, ${ }^{43}$ including one established AMS user, one making the transition from conventional milking to AMS, and one agriculturalcollege farm which was running conventional milking and AMS in parallel for comparative and educational reasons. These farms varied in size, with herds of between approximately sixty and 240 milking cows. Herds were of mixed ages, from newly introduced heifers to cows with histories of several lactations. Most were the familiar black-and-white Holstein-Friesian cattle, although we also encountered other breeds, and AMS manufacturers are keen to emphasize how their machines can milk any breed, from the larger black-and-whites to smaller breeds such as Jerseys. Alongside this on-farm research, we interviewed those involved in the research, development and marketing of AMS, and veterinary and other scientists researching milking technologies and other aspects of dairy cow management, health and welfare. Based on this research we have examined elsewhere the emergence of particular kinds of bovine agency and subjectivity in relation to robotic milking, the imposition of particular kinds of discipline on cows which counter the rhetoric of freedom mentioned above, ${ }^{44}$ the contingent and 'situated' ethics which are brought into effect alongside the introduction of AMS, ${ }^{45}$ and the need for farmers (and other humans) involved in the system to learn new skills (for example in the use of computers and the analysis of data produced by AMS) and to deploy their stockmanship in new ways. ${ }^{46}$

What is clear is that the historical concerns surrounding mechanized milking identified in the previous section persist with the introduction of AMS. As the next sections will show, the impact of AMS on the experience and subjectivity of both cows and humans, its influence on human-cow relationships and its implications for health and welfare are significant. By exploring the ways in which the farmers in our study articulated these themes, we show how the scientific and technological processes involved in creating AMS are constituted around, and constitute, historically situated understandings of human and cow bodies, agencies and subjectivities. Rather than being a revolutionary technology, we suggest that AMS represents an evolution in both agricultural science and human/bovine 'being'.

\section{Robotic milking technologies: changing experiences, subjectivities and relationships}

\section{Cow experience and subjectivity}

Farmers who use AMS, and AMS manufacturers, suggested that cows' experience of milking (and indeed their wider experience of living on a dairy farm, and being within a group of cattle), and their behaviour, were changed significantly by being in a herd milked by AMS in contrast to cows milked in a conventional milking parlour.

43 Christopher Bear, Katy Wilkinson and Lewis Holloway, 'Visualizing human-animal-technology relations: field notes, still photography, and digital video on the robotic dairy farm', Society and Animals (2016), doi 10.1163/15685306-12341405.

44 Holloway, Bear and Wilkinson, op. cit. (1).

45 Holloway, Wilkinson and Bear, op. cit. (1).

46 Butler and Holloway, op. cit. (34). 
Key to this was a sense that cows milked using robots gained in autonomy. As we were told by one manufacturer's representative,

Any robotic system the cows are left to their own devices. They do what they want ... the cow takes control of her own destiny.

Although this is clearly problematic, in the sense that the 'freedom' experienced by these cows is very limited and set in the context of intensive dairy farming practices, it is nevertheless suggestive of a perceived and important change in bovine subjectivity. Farmers using AMS made similar comments, as illustrated by the two farmer comments below:

The cows are very much free to do their own thing ... you just let them get on with the job, really. ${ }^{47}$

Well it's choice, isn't it? They [the cows] have the choice ... to do what they want, when they want really, don't they?

In general terms, cows' behaviour was described as being more 'relaxed', 'happy', 'quiet', 'cool' and 'chilled-out' in AMS. As one farmer said,

From day one they were just quieter, just chilled-out and happy. You're not forcing them to do anything they don't want to.

These changes can be understood as representing a change in bovine subjectivity: in what it is to be a cow in different milking systems, and in how cows are represented and related to (we return to this latter point below). The robot makes interventions in the life of the cattle as a group, which means that they act less as a herd, and more as individuals. In particular, the herd hierarchy which exists in conventionally milked herds - meaning that cows experience a social ranking which gives some animals priority in the queue to be milked or fed, and means that others experience bullying - is seen to break down in AMS groups. We were told by one farmer,

They're individuals, not a herd any more, that's the difference of milking in this system ... it breaks up the herd instinct, I think.

Thus, returning to one of the concerns raised earlier, that machine milking implies the loss of cow individuality, in some senses at least individuality is regained by the positioning of a cow in a robotically milked group. It remains questionable whether this is wholly positive; some argue, for example, that being in a herd is a key part of what it is to be bovine, wherever a cow is positioned within the hierarchy. It is clear, however, that this particular technological intervention leads to important changes in animals' subjectivity and in how they relate to each other in their group. For the farmer, calm and quiet cows facilitate management. One farmer described, for example, that the process of physically marking cows who were ready to be artificially inseminated (AI'd) (by applying a dab of colour to their backs) was easier with robotically milked herds than with conventionally milked herds: cows in the latter would attempt to move away from the

47 Farmer names are withheld in order to protect confidentiality. 
human because they were used to being herded around, cows in the former would stand still as the human approached. In robotically milked herds, cows will simply stand in the barn for AI, while in conventionally milked herds the cows have to be herded into a crate or 'crush' to hold them still.

However, this regaining of individuality and change of subjectivity is not all benign. Identified individually, each cow's specific and individual performance is monitored and recorded by the AMS, allowing problematic behaviour to be identified and interventions to be made. Here, individuality is not simply associated with freedom to choose when to be milked, but becomes associated with a responsibility to be productive: to visit the robot for regular milking, and to deliver high-quality milk in acceptable volumes. One farmer, for instance, discussed this in terms of his own job being to help cows to 'achieve' what they were able to. Cows may also be regarded through the prism of the machine which is milking them. Claims are made that robots produce more efficient dairy farming systems, for instance, and the cows are expected to play their part in maintaining that efficiency, for example by presenting themselves to be milked regularly so that the farmer does not have to be 'summoned' by the robot to find cows defined as 'lazy', take them to the AMS and ensure that they are milked. Cows are similarly described in ways which associate them with the language also used to describe the technology. For instance, one farmer said,

If you don't maintain your animal, it [the system] will not work. It will work in a fashion but it'll not function as it should do.

Another farmer discussed how the cows' rumen function needed to be managed through correct feeding, to maintain their productivity. In this kind of discourse, the cow is to be maintained like other equipment to ensure efficient system operation. In cases like these, then, the concerns of people like Collis and Seymour re-emerge in this new technological context, with the cow's animality subsumed by the demands of the technology and the farming system. Particular kinds of cow body might be chosen, and indeed selectively bred, to suit the robot. For example, the robot finds it easier to milk cows with certain udder shapes and teat sizes, and the whole system is better suited to high-yielding cows who will visit the robot several times per day. Additionally, just as cows 'disappear' from view in the conventional milking parlour, one Dutch AMS developer described how, while giving talks to farmers on the benefits of robotic milking, he would be asked, 'do you see the cow between all that iron?' While AMS might grant cows individuality, images of the technology in use show that the cow becomes rendered almost part of the robot during the milking process: she enters the AMS stall, which closes around her, confining her and presenting her in the best way for the robot arm to swing in and perform the actual milking.

While thus enclosed, detailed data, going well beyond what is recorded in conventional milking, are collected. AMS takes the granularity of the data recorded beyond that of conventional milking; for example, it records the quality and amount of milk taken from each quarter of the udder, as opposed to the udder as a whole. Data collected is used to monitor more intensively the bodies and performance of individual animals. For example, one farmer described how 
the computer will [record] deviation in yield, low activity; we've activity collars on the cows ... we look for deviation in milk yield. If there's like 20 per cent deviation, 60 per cent whatever, and just check her out, look at her conductivity, ${ }^{48}$ when she was last milked to see if there was anything going [on] ... and then see what we're going to do with her if we need to do anything.

What is increasingly evident here is a process of normalization, ${ }^{49}$ as an expected level of productivity is established, against which individual performance can be measured. In this way, farmers using AMS discuss how they are able to more effectively pick out and manage 'deviant' cows, perhaps identifying them as in need of veterinary treatment, as 'lazy' and needing human intervention to take them to the robot, or as unsuitable for robotic milking and thus potentially removed from the herd.

In this way, bovine experience, behaviour and subjectivity are altered by, and reconstituted around, the intervention of robotic milking. Although this can be presented as benign - cows gain freedom and choice, avoid the bullying of herd hierarchies and can behave in more 'natural' ways - we suggest that other effects of the individualization of cows include an ability to manage and discipline what Foucault refers to as 'counterconduct' 50 more closely in new, technologically mediated ways. In this sense, we might understand cows as becoming subject to the robot, rather than simply gaining a subjectivity previously withheld. As in the shift from hand to machine milking, then, what it is to be a cow is altered again by the introduction of AMS.

\section{Human experience and subjectivity}

At the same time as bovine experience and subjectivity alter with changes in milking technology, so do those of the humans involved, just as they did in the earlier shift from hand to machine milking. As noted above, John Seymour viewed machine milking as unpleasant, monotonous work. Robotic milking automates the milking process, relocating the actual labour involved in milking from a human to a machine, to the extent that humans need not be directly present during milking (which, after all, is likely to be going on twenty-four hours a day in an AMS). Indeed, the improvements to quality of life that this offers are presented as one of the main advantages of AMS by both manufacturers and farmers. Farmers are no longer tied to fixed milking times and to hours in the milking parlour (or, alternatively, tied to the complexities of finding and managing good-quality staff to perform the milking), freeing them to perform other work or to participate more fully in family and social life. The robots and cows can be monitored remotely. Interviewees argued that, indeed, automated milking is preferable to either hand or (conventional) machine milking. For example, AMS manufacturers said,

milking is ideally suited to robot technology. I mean, it's a poor use of somebody's time, it's a difficult job, but it's a job that's done by a robot much better than a human could do it if it's done well ...

48 Milk's electrical conductivity is automatically measured by the AMS and indicates the presence of mastitis.

49 Michel Foucault, The History of Sexuality, vol. 1: An Introduction, Harmondsworth: Penguin, 1990.

50 Michel Foucault, Security, Territory, Population, Basingstoke: Palgrave Macmillan, 2007. 
years ago when people were milking by hand they probably didn't think a machine could actually get the milk out of a cow in the same way they could with their hand. That transition probably took quite a few years and this is just another step forward as well really.

And yet, as with the cows, the effect of AMS is not simply to 'free' the farmer. Humans become tied to the robots in other ways, and their subjectivity, and what is expected from them as farmers, change. Their relationships with their cows change too, as discussed in the next section. Most immediately, AMS is programmed to alert farmers via their mobile phones if a technical problem arises. Farmers are thus liable to be contacted at any time, and they commented that this could disrupt their other activities and their 'free' time or sleep. Similarly, farmers might expect to lose control, to a degree, of their autonomy, by being directed towards certain cows and/or tasks by the data recorded by the robot.

More widely, what farmers are expected to be able to know and do is significantly changed. Their stockmanship is revealed in new ways in relation to the robotic system, as illustrated in the following comment from an AMS user:

You need to be looking at the records and the computers twenty-four hours a day effectively, so everybody needs to know what everybody else is doing ... everybody will know how to dissect the information, the correct information, because as we're never handling these cows you've got to have a damn good stockman's eye but you've also got to be computer-literate to understand so that you can ... why has that cow not been milked? Why is there a deviation in milk? ... You've got to be able to look at the computer and dissect this so we've built a lot of reports within the system so whoever comes on first thing in the morning we've five reports that we quickly look at so that we can flag up the issues that could be occurring and the cows that need to be looked at as soon as possible. We've got lots of standard operating procedures in place and it's so important that we have that with this system.

This excerpt illustrates a number of points. First, this farmer, in common with many others, re-emphasizes the importance of 'stockmanship'. Good stockmen and -women are expected to have acquired in-depth, often tacit, knowledge about their animals. This means, for example, being able to judge the relative quality of different animals, knowing when animals are ill, or being able to predict and guide their behaviour to facilitate good management practices. Stockmen and -women are held responsible for animal health and welfare. Stockmanship is a valued quality amongst farming communities, although as its exact nature is difficult to pin down it has often been neglected in agricultural science and technological development. ${ }^{51}$ But, second, in relation to AMS, stockmanship becomes inflected in new ways by the availability of new kinds of data, the interpretation and use of which demand new and different skills. And third, the reconfiguring of cow management via AMS tends to suggest a sort of automation of human activity too: standardized reports have been created which guide activity, and people respond to the data by following standard operating procedures.

From the manufacturers' perspective, there is an apparent strategy of attempting to reconfigure the farmer's subjectivity around the robotic milking system. As one said,

51 Peter English, Gethyn Burgess, Ricardo Segundo and John Dunne, Stockmanship: Improving the Care of the Pig and Other Livestock, Ipswich: Farming Press Books, 1992; Rhoda Wilkie, Livestock/Deadstock: Working with Farm Animals from Birth to Slaughter, Philadelphia: Temple University Press, 2010, pp. 34-35. 
For a farmer who's never managed his cows properly the robot computer will force him to do so. It tells him about blood in the milk, conductivity, yield per quarter. If a cow's possibly lame it can indicate that, it tells him how many times a cow has been fed every day ... Farmers sometimes put robots in thinking that it's all automatic, it's like, you know, the cows will feed themselves automatically, and milk themselves automatically. But it doesn't work like that. And those are all the things that we've got to make sure the farmer understands.

That farmers understand this view of robotic milking is illustrated by the following comment from AMS users, who said, for example,

I think you must be really sharp up on dealing with cows. It is a personal thing, you must be extremely hard on yourself and disciplined. The robot is not an easy option.

Or:

The idea is that you put the robots in ... you've even to be a better stockman than milking cows twice a day because you've got to be able to walk in that building and see whether a cow is well, whether it's stood up, laid down, eating at the feed fence wherever it is in the building and know instantly ... you struggle to pick them up unless you actually know your cows well.

Farmers are thus expected to become skilled and knowledgeable in the use of data collected by the AMS, and to be able to combine that with their 'traditional' stockmanship to produce a better farming system overall. For those who adopt AMS, a change in identity results. Akin to studies of the increasing use of technologies in other aspects of agriculture, ${ }^{52}$ AMS farmers' experience of farming was increasingly an office-based one, using a computer to analyse data and plan action. AMS might thus be chosen by particular kinds of farmer, those with a predisposition towards computers and data analysis, but at the same time might re-create farmers as subject to the computer, in a similar way to the subjectification of cows to the AMS, as the following comment from a conventionally milking farmer notes:

I always think the successful robot people have got a slightly different mindset because they're into technology and they're into computers ... but I'm not one of these people that can sit and go through pages on a computer. I'd rather we were doing something else ...

Just as with cows, the subjectivity of farmers and their experiences of farming are reconstructed around AMS. As with cows, this can be represented in a positive light, and indeed is so by manufacturers and by farmers who have adopted AMS. However, AMS use also reconstitutes human-cow relationships, moving these relationships on again from their constitution around conventional milking machines.

\section{Human-cow relationships}

As is implied above, the introduction of AMS leads to quite radical shifts in human-cow relationships. AMS in some ways furthers the distancing of humans from cows suggested by both Collis and Seymour. During hand milking, close and regular physical contact

52 See, for example, Judith Tsouvalis, Susanne Seymour and Charles Watkins, 'Exploring knowledgecultures: precision farming, yield mapping, and the expert-farmer interface', Environment and Planning A (2000) 32, pp. 909-924. 
was established between human and animal, and conventional machine milking requires humans and cows to be co-present even if the actual physical contact between them is diminished. Robotic milking means that humans are no longer directly present during milking, and thus opportunities for embodied contact are reduced. As noted, this is not necessarily seen as a negative change, and is linked to gains in 'freedom' for both people and cows. However, for some, and particularly for those farmers critical of AMS, the loss of close contact with their cows impacts on their ability to monitor health and productivity. There is thus a new anxiety associated with AMS - that a distanciated relationship between humans and cows might potentially be linked to neglect (something denied by AMS advocates, who, as seen above, emphasize the need for good stockmanship) and that the direct, embodied and regular contact associated with good cow management will be lost.

Importantly, however, the introduction of robots does not simply extend a historical trajectory of progressive distanciation, but instead restructures human-cow relationships so that stockmanship and care are produced in new ways made possible (or necessary) by the intervention of AMS technology. There are, briefly, two dimensions to this.

First, robotic milking systems produce great quantities of data about each individual cow. Manufacturers argue that the availability of this data allows farmers to know, in much more detail than was previously possible, each cow's individual health and productivity. While for some AMS-using farmers there is a feeling of data overload, AMS use demands an ability to use data to plan cow management, for example in terms of feeding, AI or veterinary treatment. AMS can thus be associated with a different kind of close, intensive, technologically mediated human-cow relationship.

Second, and contrastingly, AMS advocates argue that the 'freedom' from the labour of performing actual milking can give farmers more time to simply observe and be with their cows. Thus, instead of simply seeing cows' udders and rear ends during milking in a parlour, AMS users can see their cows as 'whole animals' as they move around their living areas, feed, go to be milked, interact with other cows, rest and so on. As one farmer said, describing how he combined observation of his cows with use of robot-generated data,

[It's] just management, just looking at the cows' feet, looking at whether they're chewing the cud, whether they've got shiny coats ... [and] all the information that I get from a computer telling me what various things there are that I can look at to help me manage the cows better really.

Again, then, instead of there being a simple trajectory from the close contact associated with hand milking, through progressively more distanciated relationships associated with the evolution of mechanized milking, AMS would seem to permit (for those farmers who choose to do so) the establishment of observational routines which allow for a reconnection of people with their cows as individual whole organisms.

The following excerpts from an interview with two brothers managing a robotically milked herd exemplify some of these points. Responding to comments from farmers milking conventional herds that they wouldn't know their cows as well once they started using AMS, one said, 
Well, we find it's exactly the opposite because we're out now in the shed and we're seeing the whole cow not just that little triangle that you see in the milking parlour. I tend to think that we know the cows a lot better than we ever knew them before when we were in the milking parlour.

With regard to the creation and use of information, he went on to comment,

I tend to think now that you do actually pick up problems quicker because you know there's a list that tells you on the computer how long a cow has been until she last milked and the more you get to know your cows you look down this list and you think ... she hasn't been in for the last eighteen hours what on earth's wrong with her, you see? You tend to go straight to her, whereas [in conventional milking] you may not have seen her until the next morning ... that is completely the opposite to what I thought it would be; I thought you would be struggling to find problems with the cows. I thought you'd be missing things ...

Rather than simply confirming anxieties that continued automation and mechanization will lead to a loss of the human-cow relationship and an associated deterioration in stockmanship, then, AMS might act to enhance a stockman or -woman's ability to know and care for their cows.

Similarly, anxieties such as those of Collis - that as automation proceeds in dairy farming cows will increasingly be framed as machine-like entities - are simply not confirmed by the actual use of AMS in practice. Although cows do become more intensively entwined with machines, and are surveilled by machines in ways which can lead to interventions in their lives, at the same time individual and group bovine subjectivity can be expressed in new ways facilitated by the AMS and its reordering of the life of the cows. This effects changes too to human-cow relationships. One AMS user described, for example, the change in his cows following the move to robotic milking:

When you go with the motorbike and round them up they come running up, skipping, bucking, it's like you're rounding young stock up ... which we'd never seen cows do before because whenever you went to round them up they were all busting with milk, uncomfortable, whereas now you would be rounding cows up that had only been milked an hour before. So yeah, it was a pleasure to fetch the cows in.

The shifts in the human-cow relationship described here have important implications for cow health and welfare. As noted, diseases such as mastitis have been a persistent issue in dairying, consistently inflecting debates about the best milking technologies and practices. AMS advocates argue that robotic milking reduces mastitis levels, and is thus better for cows. We suggest that in practice things are rather more complex.

As noted above, Woods argues that mastitis is framed differently depending on which scientific knowledge practices are brought to bear on it. ${ }^{53}$ In effect, 'mastitis' is a different entity, and is treated differently, when seen through different scientific lenses. The framing of mastitis from the late 1920 s through to 1980 as a problem of production rather than one of cow health hampered the implementation of effective control practices. In AMS, mastitis becomes something different again. It is reframed as something technologically observable, recorded at a finer level of granularity than was previously

53 Woods, op. cit. (4). 
possible, and more preventable via the application of standardized, mechanized uddercleaning and post-milking disinfection processes. The automation of the process and the ability of the robot to assess each udder quarter individually enhances farmers' ability to intervene effectively. This was affirmed by farmers. One said, for instance, that the robot allowed him to observe how effective mastitis treatment actually was: he had tried a new brand of treatment and could observe on a quarter-by-quarter basis its effect on a cow's infection compared with previous treatments.

And yet the argument that simply introducing a robot will necessarily improve cow health and herd productivity is simplistic. The robot, by itself, does not cause improvements; human agency and bovine embodiment remain significant. As noted, particular kinds of human subjectivity are co-produced with the introduction of robots, and thus, in order to effect improvements, AMS requires particular kinds of people to be involved and particular practices (such as effective use of data) to be instigated. Particular kinds of cow are also needed, e.g. those with udders most suitable for robotic milking, those who behave in the desired fashion for AMS, and increasingly those with the right genetic characteristics such as mastitis resistance along with high milk yields. A more complex picture begins to emerge from empirical research, then, which builds on the historical trajectory already outlined. There isn't a simple causal relationship between a technology or practice and health and productivity in dairy farming; instead, health and productivity outcomes are the result of complex relationships between people, cows and technologies. Hand, machine or robotic milking can all be hygienic and be associated with good health and productivity outcomes, but only where the 'right' people and other circumstances are in place. A problem such as mastitis cannot be simply linked to one kind of milking or another, therefore.

An interview with a dairy scientist and consultant who advised farmers on improving cow health explored this. He began by discussing teat cleaning (key to removing mastitiscausing bacteria) prior to milking in conventional parlours, and then compared this to AMS:

you go to some units and they do no teat preparation. And so with the robots at least they are getting some teat preparation, [but] whereas if a human cleans the teat and it's still not very clean what you would normally do you can go back and clean it again. With a robot it's a set time, set routine, and it doesn't look at the teat to see how clean they are.

There are no direct welfare issues with robots, provided they're installed properly and managed correctly. And that's no different to conventional milking ... You can argue that welfare should be better [using AMS] because of all the recording that's going on. But it comes back to the individual user. But yeah the main issue I still have in my mind revolves around teat preparation, that if you've got a dirty cow how thoroughly do you clean them? A human can make that judgement ... and you might pre-dip her first, do her again, try and get her clean. The robot can't distinguish that at the moment. That might change with automatic, you know, almost taking a picture of the cow's teats and making a judgement.

Comments such as this express an ambivalence towards the health and hygiene benefits of AMS, rather than simply regarding it as necessarily an improvement on conventional milking. The limits of AMS (its inability at present to distinguish between clean and dirty teats, and its standardized hygiene routines which cannot treat differently dirty teats differently) are drawn out, and compared with what a 'good' human milker might (in 
theory) do to ensure better hygiene, but also with what happens on some farms where no teat hygiene is practised at all. Compared with the (unsurprising) advocacy of AMS manufacturers, this dairy scientist's more nuanced perspective acknowledges the effects of variations in cows' and humans' bodies and agencies.

\section{Conclusions}

In this paper, we have argued that although AMS is represented as revolutionizing dairy farming, and as the future of dairying, in practice it does not simply force a break with the past, or a move into the future. The paper has attempted to destabilize that sense of rupture and instead to position AMS as part of a longer historical trajectory of change in milking technologies and practices. As milking practices have changed from hand to different kinds of machine milking, what it is to be human and bovine have changed, human-cow relationships have changed, and understandings of bovine health and welfare have changed.

This paper has illustrated the persistence of several concerns and anxieties over the course of the development of milking technologies and practices, focusing on the period from the early twentieth century when mechanized milking became commercially available and was increasingly adopted so that it was the dominant form of milking practice by the 1960s, and then on the more recent advent of robotic milking systems, commercially available from the early 1990s and now regarded as becoming the dominant form of investment in new milking technology, at least in Europe. ${ }^{54}$ These concerns have focused around issues of hygiene and cow health and welfare, and around the identities, bodies, capacities and agencies of both humans and cows as they are reconstituted around the demands and possibilities afforded by the robots. AMS was developed as a solution to some of these issues, and is presented by its advocates as successful in that regard. We have tried to show how technological change is in part based on understandings of people and cows, at the same time as bovine and human agency and subjectivity are entrained and reconfigured in relation to emerging milking technologies, so that what it is to be a cow or human is co-produced with technological change.

The paper suggests, then, that far from simply drawing a close to the history of those concerns, robotic milking and its associated information technologies rearticulate them as they emerge in new ways, creating new ambivalences around the supposed modernization and improvement they represent. In this case, an understanding of the history of those concerns is important because it draws our attention to how others have framed them in relation to different technologies and contexts, and to how different combinations of agricultural scientists, technology developers and farmers have grappled with trying to resolve problems associated with the bringing together of non-human actors - cows and milking technologies of different kinds - in order to effect 'improvements' to milking practices.

54 Joanne Pugh, 'End for the herringbone?', Farmers Guardian, 8 July 2011, at www.farmersguardian.com/ home/business/business-news/end-for-the-herringbone?/40120.article, accessed 25 July 2011. 